\title{
Hyperbaric oxygen
}

\author{
More indications than many doctors realise
}

Many British doctors are ignorant of the indications for hyperbaric oxygen and sceptical of its benefits, according to a recent survey of hyperbaric oxygen facilities. The survey, by the BMA's Board of Science and Education, concluded that given the present level of use then provision was sufficient, although doctors may be underusing the treatment. ${ }^{1}$ They need to know for which conditions hyperbaric oxygen works and refer accordingly. The telephone advisory service, run by the Institute of Naval Medicine at Gosport (similar to the National Poisons Unit help line), should be better known. ${ }^{\star}$

Treatment with hyperbaric oxygen was introduced as an adjunct to cardiovascular surgery before cardiopulmonary bypass techniques and deep hypothermia became available. But when surgery in a hyperbaric chamber was no longer necessary most of the original researchers stopped studying it. Britain helped to pioneer the use of hyperbaric oxygen to treat carbon monoxide poisoning, refractory osteomyelitis, ${ }^{2}$ and compromised skin grafts. But with no formal training programmes and little funding, the treatment now attracts little attention in Britain.

When administered at pressures greater than one atmosphere, oxygen can assume properties more akin to a drug than

$\star$ Tel 0705822351 ext 41769

Uses of hyperbaric oxygen approved by the Undersea and Hyperbaric Medical Society ${ }^{23}$

Air or gas embolism

Carbon monoxide poisoning and smoke inhalation

Clostridial myonecrosis (gas gangrene)

Crush injury, the compartment syndrome, and other acute traumatic ischaemias

Decompression sickness

Enhancement of healing in selected problem wounds

Exceptional anaemia resulting from blood loss

Necrotising soft tissue infections (of subcutaneous tissue, muscle, or fascia)

Refractory osteomyelitis

Radiation tissue damage (osteoradionecrosis)

Compromised skin grafts and flaps

Thermal burns a simple support for metabolism. In carbon monoxide poisoning, for example, it stops lipid peroxidation, which spares neuronal cell membranes. ${ }^{3}$ It reduces oedema by about $50 \%$ in post ischaemic muscle through preserving adenosine triphosphate. ${ }^{4}$ In acute burns it reduces fluid requirements by $35 \%$ in the first 24 hours, thus reducing oedema. ${ }^{5-8}$ It reduces white cell adhesion to capillary walls after ischaemic or traumatic insult, mitigating the no reflow phenomenon. ${ }^{9}$ Red cell flexibility is doubled in about 15 treatments. ${ }^{10}$ White cell killing of aerobic bacteria and some fungi is greatly enhanced at high oxygen pressures, ${ }^{11}$ facilitating control of osteomyelitis ${ }^{12}$ and reducing the number of operations and mortality in necrotising fasciitis. ${ }^{13}$ Extremely important is its stimulation of new capillary and collagen formation in radiated tissue, normalising tissue oxygen tensions to permit surgery, healing, and even bone grafting. ${ }^{14}{ }^{15}$ Finally, it increases tissue levels of superoxide dismutase, which counters the formation of free radicals after injury, resulting in better tissue survival. ${ }^{16}$ This is particularly important in crush injury, replants, and grafts, where free radical formation is responsible for reperfusion injury. ${ }^{17}$

Although many doctors believe that good research on hyperbaric oxygen is rare, the converse is true. ${ }^{18-22}$ Over 3800 papers have been published on the topic despite the relative scarcity of chambers. The Undersea Medical Society began investigating the claims being made for hyperbaric oxygen treatment in 1977. A committee (which I chaired) considered 64 different disorders allegedly improved by treatment with hyperbaric oxygen. In most of them there was insufficient evidence to warrant its clinical use.

In preparing our original report we consulted the largest private insurers in the United States, Blue Cross/Blue Shield, and the Federal Health Care Finances Administration. Since then the report has been continually updated. At present only 12 conditions are approved by the society for reimbursement. ${ }^{23}$ Since 1977 the number of clinical chambers in the United States has grown from 37 to nearly 300 .

For inclusion on the approved list there had to have been controlled studies or large clinical series indicating not only the efficacy but also the cost effectiveness of treatment with hyperbaric oxygen. In disorders for which prospective controlled trials were impossible or unavailable, evidence adduced for the efficacy of hyperbaric oxygen had to be at least as convincing as that used to support reimbursement of other treatments routinely paid for by insurers. The five major British centres for the most part limit treatment to those 
disorders on the approved list, despite there being no regulation to that effect.

This list can serve only as a guide. Though quite useful in diabetic wounds, hyperbaric oxygen is only part of a programme of total wound care. For some diabetic wounds hyperbaric oxygen is inappropriate if the large vessels distal to the trifurcation at the knee are occluded or severely stenotic. Crush injury and impending compartment syndrome need to be treated immediately if any worthwhile result is to follow. Late referral, which gives time for oedema, reperfusion, and injury; free radical damage; and the no reflow phenomenon to do their work, makes the treatment largely a waste of time and money. For some surgical patients the potential dangers of further trauma to the wound during transportation will militate against the use of hyperbaric oxygen. Experience has shown, however, that patients with severe carbon monoxide poisoning can be transported safely over long distances in a properly equipped ambulance or helicopter.

Before transfer of a critically ill patient is contemplated it should be ascertained that the receiving chamber facility can deliver the necessary level of intensive care. Whenever the use of hyperbaric oxygen is considered, consultation with the physician in charge of the hyperbaric oxygen facility is mandatory to ensure that referral is appropriate. The timing of hyperbaric oxygen in relation to surgery is also critically important. For example, in necrotising fasciitis, surgery is the accepted primary treatment, with hyperbaric oxygen used as a follow up. With gas gangrene, however, the hyperbaric chamber is used before surgery (other than for fasciotomy). In the treatment of radionecrosis the patient should be treated at least 20 to 30 times in the chamber, to induce the formation of new capillaries, before elective surgery is performed if healing is to be expected.

ERIC P KINDWALL Director of hyperbaric medicine

Departments of Plastic and Reconstructive Surgery

and Pharmacology and Toxicology,

Medical College of Wisconsin,

Milwaukee,

Wisconsin 53226

United States
1 BMA Board of Science and Education. Clinical hyperbaric medicine facilities in the UK. London: BMA, 1993.

2 Perrins DJD, Maudsley RH, Colwill MR, Slack WK, Thomas DA. OHP in the management of chronic osteomyelitis. In: Brown IW, Cox BG, eds. Proceedings of the third international conference on hyperbaric medicine. Washington, DC: National Academy of Sciences, National Research Council, 1966:578-89. (Publication 1404.)

3 Thom SR. Antagonism of carbon monoxide-mediated brain lipid peroxidation by hyperbaric oxygen. Toxicol Appl Pharmacol 1990;105:340-4.

4 Nylander G, Lewis D, Nordstrom H, Larsson J. Metabolic effects of hyperbaric oxygen in post-ischemic muscle. Plast Reconstr Surg 1987;79:91-6.

5 Cianci P, Lueders HW, Lee H, Shapiro RL, Sexton J, Williams C, et al. Adjunctive hyperbaric oxygen therapy reduced length of hospitalisation in thermal burns. $f$ Burn Care Rehabil 1989;19:432-5.

6 Nylander G, Nordstrom H, Eriksson E. Effects of hyperbaric oxygen on oedema formation after a scald burn. Bums 1984;10:193-6.

7 Stewart RJ, Yamaguchi YT, Cianci PA, Knost PM, Samadani S, Mason SW et al. The effects of hyperbaric oxygen on adenosine triphosphate in thermally injured skin. Surgical Forum 1988;39:87-90.

8 Wells $\mathrm{CH}$, Hinton JG. Effects of hyperbaric oxygen on post-burn plasma extravasation. In: Davis JC, Hunt TK (eds). Hyperbaric oxygen therapy. Bethesda, Maryland: Undersea Medical Society, 1977:259-65.

9 Zamboni WA, Roth AC, Russell RC, Graham B, Suchy H, Kucan JO. Morphological analysis of the microcirculation during reperfusion of ischemic skeletal muscle and the effect of hyperbaric oxygen. Plast Reconstr Surg 1993;91:1110-23.

10 Mathieu D, Coget J, Vinckier F, Saulnier A, Durocher ET, Wattel F. Red blood cell deformability and hyperbaric oxygen. Med Subaquatique Hyperbar 1984;3:100-4.

11 Mader JT, Brown GL, Gluckian JC, Wells CH, Reinarz JA. A mechanism for the amelioration by hyperbaric oxygen of experimental staphylococcal osteomyelitis in rabbits. $f$ Infect Dis 1980;142:915-22.

12 Davis JC, Heckman JD, DeLee JC, Buckwold FJ. Chronic non-hematogenous osteomyelitis treated with adjuvant hyperbaric oxygen. I Bone foint Surg $[A m]$ 1986;68:1210-7.

13 Riseman JA, Zamboni WA, Curtis A, Graham DR, Konrad HR, Ross DS. Hyperbaric oxygen therapy for necrotising fasciitis reduced mortality and the need for debridements. Surgery 1990;108:847-50.

14 Marx RE, Johnson RP. Problem wounds in oral and maxillofacial surgery: the role of hyperbaric oxygen. In: Davis JC, Hunt TK, eds. Problem wounds: the role of oxygen. New York: Elsevier Science Publishing, 1988:65-125.

15 Marx RE, Johnson RP, Kline SN. Prevention of osteoradionecrosis: a randomised prospective clinical trial of hyperbaric oxygen versus penicillin. $₹$ Am Dent Assoc 1985;111:490-554.

16 Kaelin CM, Im MJ, Myers RA, Manson PN, Hoopes JE. The effects of hyperbaric oxygen on free flaps in rats. Arch Surg 1990;125:607-9.

17 Manson PN, Anthenelli RN, Im MJ, Bulkley GB, Hoopes JE. The role of oxygen-free radicals in ischemic tissue injury in island skin flaps. Ann Surg 1983;198:87-90.

18 Daris IC Hyperbaric oxyen therapy. Intensive Care Med 1989;4:55-7.

19 Goulon M, Barois A, Rapin M, Nouailhat F, Grosbuis S, LaBrousse J. Intoxication oxycarbonee et anoxie aigue par inhalation de gaz de charbon et hydrocarbures. Ann Intern Med 1969;120: anoxie a. $335-49$.

20 Hart GB, Lamb RC, Strauss MB. Gas gangrene 1: a collective review. I Trauma 1983;23:991-5.

21 Kindwall EP. Uses of hyperbaric oxygen therapy in the 1990s. Cleve Clin 7 Med 1992;59:517-28.

22 Strauss MB, Hargens AR, Gershuni DH, Greenberg DA, Crenshaw AG, Hart GB, et al. Reduction of skeletal muscle necrosis using intermittent hyperbaric oxygen in a model compartment syndrome. 7 Bone foint Surg [Am] 1983;65:656-62.

23 Thom SR. Hyperbaric oxygen therapy: a committee report. Bethesda: Undersea Hyperbaric and Medical Society, 1992.

\section{Primary care and public health}

\section{Too far apart}

In Britain primary care and public health have their roots in the early nineteenth century: general practitioners evolved from surgeon-apothecaries, and the public health movement emerged in response to the problems of urbanisation. Divergent for so long, their paths should be coming closer together.

Personal preventive services, such as immunisation and family planning, were made the responsibility of medical officers of health in 1919, ${ }^{1}$ but item of service fees under the NHS encouraged general practitioners to provide such services. In 1990 general practitioners were made responsible for health promotion and disease prevention for the first time. Their objections to the new contract were not so much because of this extension of general medical services, but because it rewarded them for doing things for which there was little or no scientific support. ${ }^{2}$ At the time there was little response from public health medicine, but three years later health promotion is being rethought.

In 1974 the Faculty of Community Medicine emphasised a management role that excluded those with clinical responsibilities. At the same time medical officers of health were replaced by medical officers who were advisers rather than advocates for the public health. However, it was not found necessary to rely on community medicine specialists for top management positions in the Griffiths reorganisation, ${ }^{3}$ and it seemed that the speciality had lost its way. The response was the Acheson report of 1988, ${ }^{4}$ which recommended a change of name to public health medicine. Its role was to set targets, allocate resources, evaluate progress, control communicable diseases, and promote health. Directors of public health were meant to be the main source of medical advice for health authorities.

There is now role confusion in both branches of the profession. Some of the administrative complexities of the new general practice contract, intended to increase competition, have had the unintended effect of making general practitioners wonder if they would not be better off as a salaried service. Many are ambivalent about health 